\title{
EVIDENCE FOR EXCESS PORE PRESSURES IN SOUTHWEST INDIAN OCEAN SEDIMENTS
}

\author{
Dallas Abbott, William Menke, Michael Hobart, and Roger Anderson ${ }^{1}$
}

Lamont-Doherty Geological Observatory of Columbia University, Palisades, New York 10964

\begin{abstract}
Brown clay cores from the Madagascar and Crozet basins show the following evidence of excess pore pressures: large amounts of flow-in, increasing average sedimentation rate with age, and nonlinear temperature gradients. Additionally, many hilltops in these basins have no visible sediment cover. The bare hilltops may result from perlodic slumping caused by excess pore pressures. Calculated excess pore pressures which equal or exceed the overburden pressure were inferred from water fluxes predicted by nonlinear temperature gradients and laboratory permeability measurements by using Darcy's law. Since pore pressures which exceed the overburden pressure are unreasonable, we attribute this discrepancy to laboratory measurements which underestimate the in situ permeability. The widespread presence of overpressured sediments in areas of irregular topography provides a process for resuspension of clay-sized particles. This mechanism does not require high current velocities for the erosion of clay and therefore can be applied to many areas where no strong currents are evident. Carbonate-rich sediments from the Madagascar Ridge, the Mozambique Ridge, and the Agulhas Plateau had almost no flow-in and occurred in areas where all topography was thickly draped with sediment. Since the age and tectonic location of the ridges and plateaus preclude water circulation in the basement, we attribute these differences between the brown clay and the carbonate-rich material to an absence of significant excess pore pressures in the plateau and ridge sediments.
\end{abstract}

\section{Introduction}

Nonlinear temperature profiles have been observed at several locations in the oceans [Anderson et al., 1979]. There are a number of mechanisms which may cause such gradients: e.g., large thermal conductivity changes with depth, water movement through the sediments, bottom water temperature changes, and internal heat generation in the sediments. Although each of these mechanisms may be applied to certain examples, convection of water through the sediments best explains the heat flow pattern in young oceanic areas [Anderson et al., 1977]. The areas in the Indian Ocean where convection is probably the primary cause of nonlinear temperature profiles have the following characteristics: (1) the basement age is young, $55 \mathrm{~m} . \mathrm{y}$. or less, (2) sediment cover is thin, generally less than 150-250 m, and (3) the observed average apparent heat flow is much less than that predicted by theoretical conductive models of heat transfer [Parsons and Sclater, 1977]. (Because the theoretical models predict the increase in depth of the

\footnotetext{
$1_{\text {Also at }}$ the Department of Geological Sciences, Columbia University, New York 10027.
}

Copyright 1981 by the American Geophysical Union. oceanic crust away from oceanic ridges, we belleve that these models adequately represent the total heat loss of the oceanic lithosphere.) When the heat transfer due to convection of water through the sediments is added to the conductive component, the average heat flow in these areas approaches the theoretical prediction. The fact that inclusion of convection in the top surface of an otherwise conductively cooling lithosphere allows heat flow and topography data to be consistent is itself a strong argument for a convective interpretation of the sediment temperature profiles.

The possible existence of water movement through the sediments covering the oceanic basement has Important implications for the consolidation of the sediment. If the water movement is rapid enough and the permeability of the sediment is low enough, convection of water will be accompanied by noticeable excess pore pressures. We define excess pore pressure as the in situ water pressure in excess of the hydrostatic pressure. Excess pore pressures accompanied by low permeabilities slow down the consolidation of the sediment, thus decreasing the effective weight of the overburden. Such high pore pressures can be detected by direct measurement or by looking at the variation of sediment physical properties with depth. For the data we shall discuss, the progress of consolidation is inferred from observation of physical properties.

We measured three sedimentary parameters which change systematically with depth as a result of compaction: permeability, porosity, and thermal conductivity. The total change in porosity and thermal conductivity is only a few percent in our piston cores: scarcely higher than the error of measurement. In contrast, permeability of ten changes by an order of magnitude within $10 \mathrm{~m}$, while the relative error remains at 5 to $25 \%$. It is for this reason that we have chosen permeability profiles as a tool with which to observe consolidation.

Although permeability, water movement, and consolidation are interrelated, they do not correlate perfectly. Permeability is affected by grain size distribution as well as by the porosity of the sediment. Consolidation is affected not only by permeability and water movement but also by the sedimentation rate and the total sediment thickness. These factors must all be considered when using permeability versus depth profiles to study consolidation.

The cores used in this study are from the Southwest Indian Ocean (Figure 1). Two broad types of sediment exist in the cores: brown clays and calcareous sands and muds. The brown clays are from 18 to $55 \mathrm{~m} . \mathrm{y}$. old oceanic crust in the Crozet and Madagascar basins [Schlich, 1975]. The calcareous sands and muds are from the Agulhas Plateau, the Madagascar Ridge, and the Mozambique Ridge, all of which are at least 55 and probably in excess of $80 \mathrm{~m} . \mathrm{y}$. old [Salto et al., 1974; Simpson et al., 1972]. The environments of the two sediment types are quite different. The brown clays are all from areas where basement outcrops are visible and the 


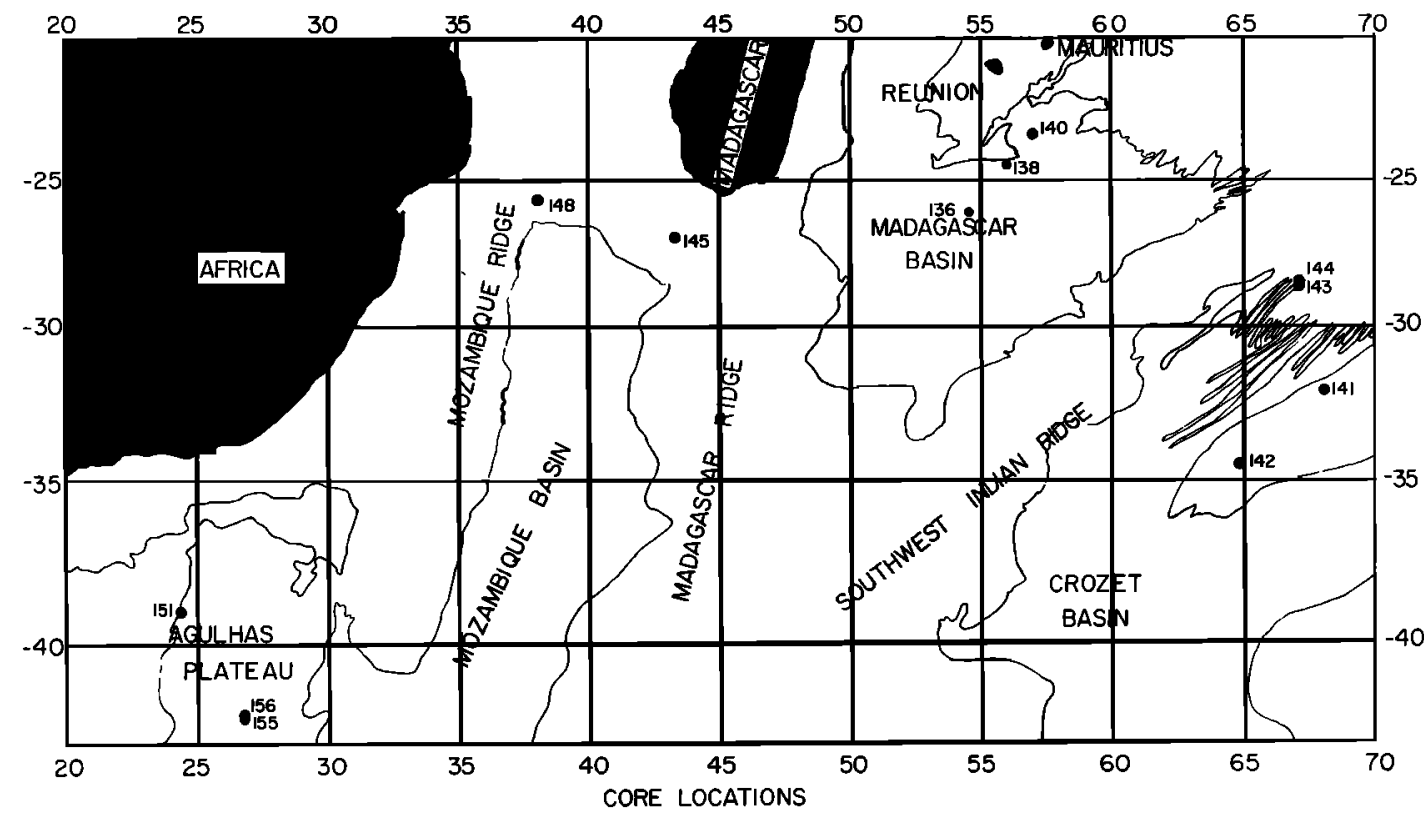

Fig. 1. Dots are locations of piston cores taken in the Southwest Indian Ocean during Vema 3409,3410 , and 3411 .

maximum sediment thickness is less than $250 \mathrm{~m}$. The calcareous sands and muds are located in places where the sediment thickness greatly exceeds $250 \mathrm{~m}$. and outcropping acoustic reflectors are not basalt basement [Tucholke and Carpenter, 1977]. The difference in the environment of the two sediment types should result in different consolidation histories.

Although sedimentation rates are slightly higher In the calcareous sands and muds than in the brown clays, the accumulation rate in both areas is much lower than the $85 / \mathrm{m} / \mathrm{m} . \mathrm{y}$. rate which Trabant [1977] found to be the maximum sedimentation rate for normally consolidated sediments. That is, all sediments with sedimentation rates higher than $85 \mathrm{~m} /$ m.y. were found to be underconsolidated due to excess pore pressures induced by impeded dewatering of rapidly accumulating sediment [Trabant et al., 1975; Keller and Bennett, 1973]. Therefore in both reglons, excess pore pressures caused by rapid sedimentation are unlikely.

The difference in age and total sediment thickness between the two groups of sediment results in totally different expectations for water movement caused by convection. The brown clays are from areas where nonlinear temperature gradients are most 11 kely to be the result of water movement. Water movement through the calcareous sands and muds is unlikely to be rapid enough to affect temperature profiles or consolidation in surface sediments serfously, since the total sediment thicknesses are too great and the crust is too old to support an active convective system. Because of these major differences we will inttially examine the brown clays and the calcareous sands and muds separately.

\section{Brown Clays}

The cores from the Madagascar and Crozet basins were taken as part of a program which Included detailed heat flow surveys of small areas [Anderson et al, 1979]. Each of the four areas surveyed had a slightly different character and heat flow pattern.

Cores 144 and 143 are from an $18 \mathrm{~m} \cdot \mathrm{y}$. age survey area in the Crozet Basin. This was the youngest area surveyed, with about 10-20 m of sediment draping the basement. The steeper hillsides and some hilltops have no sediment cover at all (Figure 2 and Figure 3 ). The $3.5-\mathrm{kHz}$ precision depth recorder (PDR) records for cores 143 and 144 show the irregular sediment cover particularly well (Figure 3). The area fust downslope of core 143 has a hump of sediment which may well be a slump or slide block. Slumps and slides are characterized on 3.5-kHz PDR records by irregular hummocky surfaces of low reflectance and lack of internal layered reflections [Embley and Jacob1, 1977]. The sediment of low reflectance at the base of the slope where core V34-144 was taken could also be a slide mass. The top of the slope in the area of core V34-143 and the slope to the right show sediment thicknesses of up to $55 \mathrm{~m}$, even though the hill is of ten steeper than at v34-143. Although the lack of sediment on the sides of the hills at V34-143 and V34-144 could be due to current erosion, such erosion is generally most evident at the bases of slopes rather than on hillsides. We therefore believe that some other mechanism than current erosion is causing the uneven sediment distribution in the vicinity of cores V34143 and V34-144.

In the $18 \mathrm{~m} . \mathrm{y}$. survey area, 13 temperature gradients out of 20 were nonlinear. Even corrected for convection, the heat flow does not reach the theoretical; perhaps because the areas of open rock act as chimneys. Core V34-143 was not accompanied by temperature gradient measurements but is of interest because it cored the sediment-basement interface (Figure 3). The uppermost third of the core is completely pelagic, while the remaining part of the core contained a large quantity of rock fragments. The permeabilities of the two 


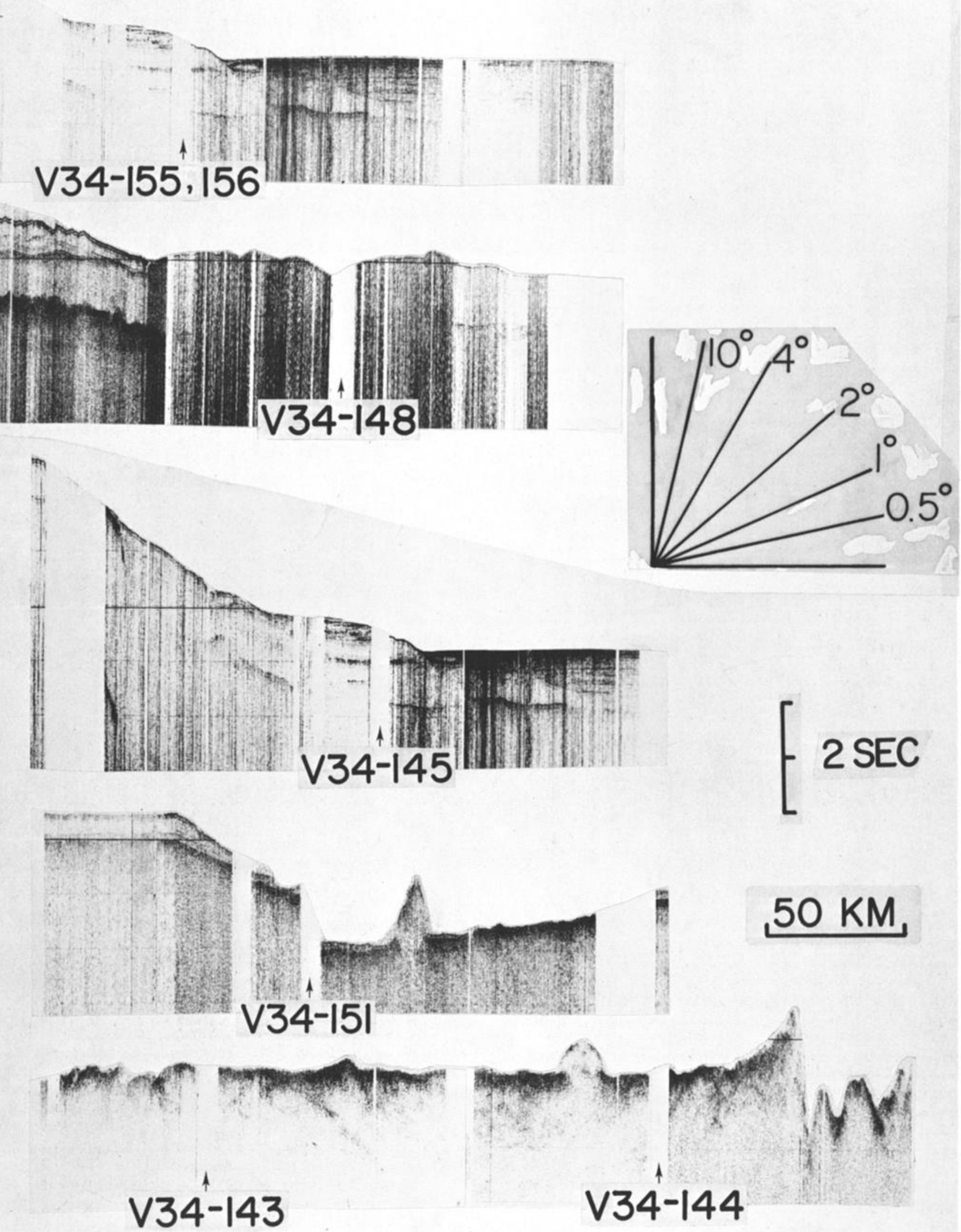

Fig. 2. Proffler records of the sedimentary environment near cores $143,144,145,148,151,155$, and 156. One second of two-way travel time equals 400 fathoms $(759 \mathrm{~m})$. The slopes and distances are calculated for a speed averaging about 9 knots $/ \mathrm{h}(16.65 \mathrm{~km} / \mathrm{h})$. 


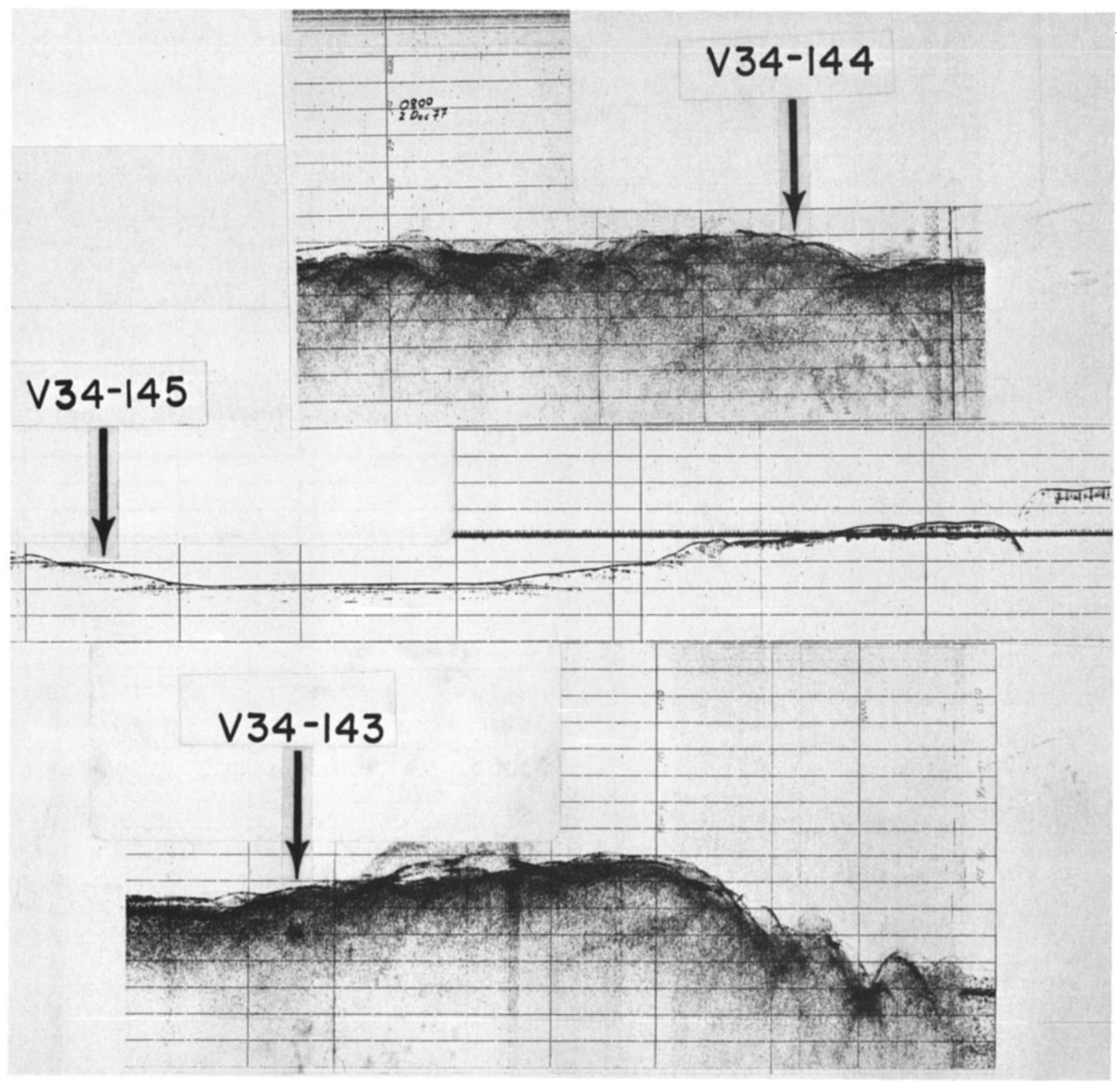

Fig. 3. The 3.5-kHz records of the sedimentary environment near cores 143,144 , and 145. One vertical division of the paper equals 20 fathoms (32.5 m).

samples with rock fragments are 3 to $10 \times 10^{-5} \mathrm{~cm} / \mathrm{s}$, about 2 orders of magnitude higher than the permeability value measured for pelagic material ( $8 \mathrm{x}$ $\left.10^{-7} \mathrm{~cm} / \mathrm{s}\right)$. This ralses the possibility that the sediment-basement interface could serve as a conduft for water movement in areas where the bottom pelagic sediment is too impermeable for direct upward movement. Such a system would 'vent' where the sediment cover is thinnest.

Core 144 is from near the top of a small rise with thinner sediment cover than the surrounding area (Figure 3). The temperature profile from this core is nonlinear, implying a water movement rate of about $6 \times 10^{-7} \mathrm{~cm} / \mathrm{s} \pm 15 \%$ [Bredehoeft and Papadopulos, 1965]. We feel that using such a steady state model is justified because the sedimentation rate in the area $1 \mathrm{~s}$ at most $4 \mathrm{~m} / \mathrm{m} .9$. and the sediment thickness is less than $250 \mathrm{~m}$. Any traisient flow or moving boundary effects caused by sedimentation are thus spread over extremely long time periods. In contrast, the water movement rate we Infer is about a centimeter per year, more than $10^{5}$ times greater than the sedimentation rate. Our permeability values as given are actually hydraulic conductivites measured on a falling head apparatus. These hydraulic conductivities are corrected to the viscosity and density of sea water at $2^{\circ} \mathrm{C}$ and $500 \mathrm{~atm}$. We will continue to refer to our hydraulic conductivity as permeability.

The lowest permeability measured on core V34144 was $2 \times 10^{-7} \mathrm{~cm} / \mathrm{s}$ (Figure 4). From Darcy's law we know that the velocity of water movement $(\mathrm{cm} / \mathrm{s})$ equals the permeability $(\mathrm{cm} / \mathrm{s})$ times the gradient (dimensionless). This implies that a 

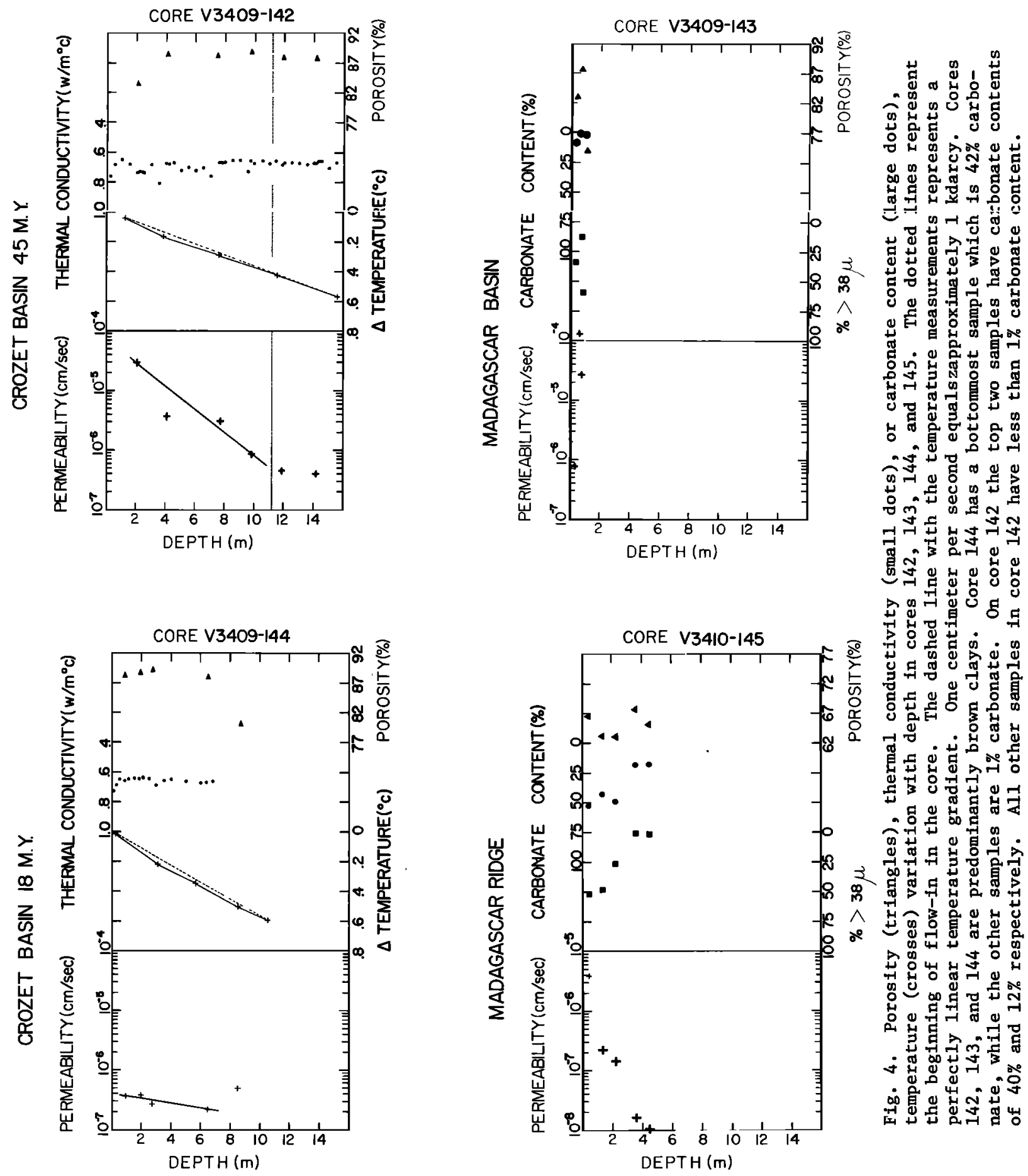

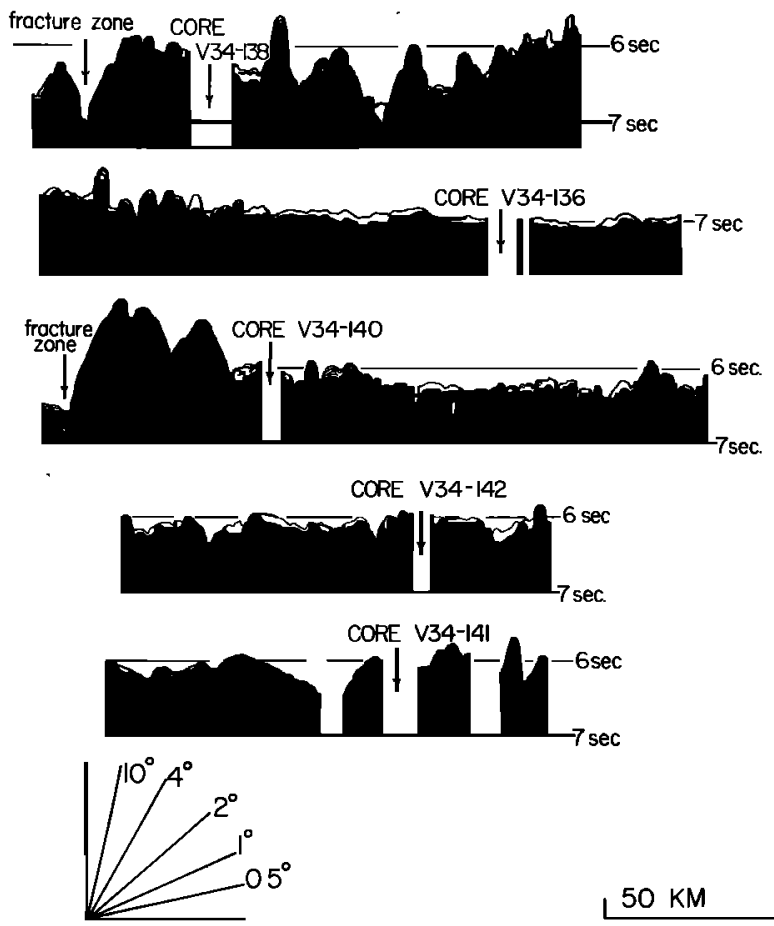

$50 \mathrm{KM}$

Fig. 5. Profiler records of the sedimentary environment in the vicinity of cores $136,138,140$, 141 , and 142. One second of two-way travel time equals 400 fathoms. The slopes and distances are for an average speed of $9 \mathrm{knots} / \mathrm{h}$.

gradient of 3 exists at the point of lowest permeability in the sediment. A gradient near zero would imply normal hydrostatic conditions; values greater than zero require excess pore pressures in the sediment.

The next heat flow survey area is on $25 \mathrm{~m} . \mathrm{y}$. old crust in the Crozet Basin (Figure 5). Of 17 temperature measurements, 10 had nonlinear gradients. The mean of all measurements when corrected for convection approaches, but is still below, the theoretical value for seafloor of this age. The sediment cover in this area is thicker than in survey 1 (about $40 \mathrm{~m}$ ), but some outcrops of basement rock still occur. These act as chimneys through which seawater transfers heat directly from basement to the ocean. The core for this area V34-141 has the greatest degree of nonlinearity observed in this study (Figure 6). The water velocity predicted by the nonlinearity of the temperature gradient is about $10^{-6} \mathrm{~cm} / \mathrm{s}$. Note that the temperature profile in this case as in all others could not be caused by the observed change in thermal conductivity. The lowest permeability measured is about $10^{-7} \mathrm{~cm} / \mathrm{s}$ (Figure 6). This implies that a gradient of 10 exists at the point of lowest permeability. This is an absurd value, implying that the excess pore pressure is 10 times the effective weight of the overburden. This discrepancy will be discussed in detail below.

Two more heat flow surveys were made, one on $45 \mathrm{~m} . \mathrm{y}$. old crust in the Crozet Basin and the other on $55 \mathrm{m.y}$. old crust in the Madagascar Basin. Both of these surveys yielded average heat flow measurements slightly greater than that predicted by the theory when corrected for the effects of convection. This slightly higher mean is of no great concern because of the limited number of measurements in the survey areas and because the heat flow values in the older portions of the Indian Ocean in general, seem to lie slightly above the theoretical values [Anderson et al., 1977].

Cores 136 and 140 in the Madagascar Basin show a semilog rate of decrease of permeability with depth (Figure 6). This semilog pattern appears in all brown clay cores which have relatively uniform carbonate and coarse fraction contents (cores $144,140,136$, and 141; Figures 4 and 6). This pattern is probably a direct result of two processes associated with compaction, deflocculation, and water loss. The permeability of a flocculated sample was found to be 3 to 60 times higher than that of a sample of identical porosity but with a dispersed structure [Lambe and Whitman, 1979, p. 291]. Water loss would put the sediment in a less flocculated state and so lower its permeability. Shearing of the sediment caused by coring disturbance would also have a similar effect.

The change in permeability also correlates with a change in porosity, since water loss in a sediment should cause a decrease in porosity. This effect is difficult to observe directly without many measurements, since the local variability of porosity is so high (about $+2 \%$ ). The brown clay core which has the steepest permeability fall off with depth (core 141) also shows the most clearcut drop of porosity with depth. Bryant et al. [1970] found strong correlation between the log of permeability and porosity with the rate of change of permeability with porosity greatest for the most coarse-grained materials. The semilog fall of permeability with depth that we observe in the brown clay cores of uniform composition 136, 140, and 141 (Figures 4 and 6) is probably best attributed to a linear change in the average porosity with depth. This change is visible in the thermal conductivity measurements for cores 142,141 , and 144, since thermal conductivity is a direct function of water content and thus of porosity in cores with a uniform carbonate content.

Deviations from this pattern of semilog permeability decay with depth appear in the top of core 142 and the base of core 144, where the sediment has a carbonate content above $1 \%$ and a higher coarse fraction, thus resulting in a higher permeability and lower porosity.

Again the heat flow results for core 141,142 , and 144 provide us with estimates of the velocity of water movement through the sediment. The nonlinearity of core 142 is small enough to be within experimental error; nevertheless, the water velocity we derive from the nonlinearity is about $10^{-7}$ $\mathrm{cm} / \mathrm{s}$. This is enough to produce a gradient of about one third at the point of lowest permeability in the core.

Discrepancy Between Velocities Determined from Heat Flow, Permeability, and Darcy's Law

Permeability measurements imply higher excess pore pressures than could be supported by the sediments, assuming the velocities of transport derived from heat flow are correct. At least three major possible causes for this discrepancy exist: (1) undisturbed clay-rich sediments have a higher cohesion intercept (cohesive strength at zero effective stress) than that measured in lab- 

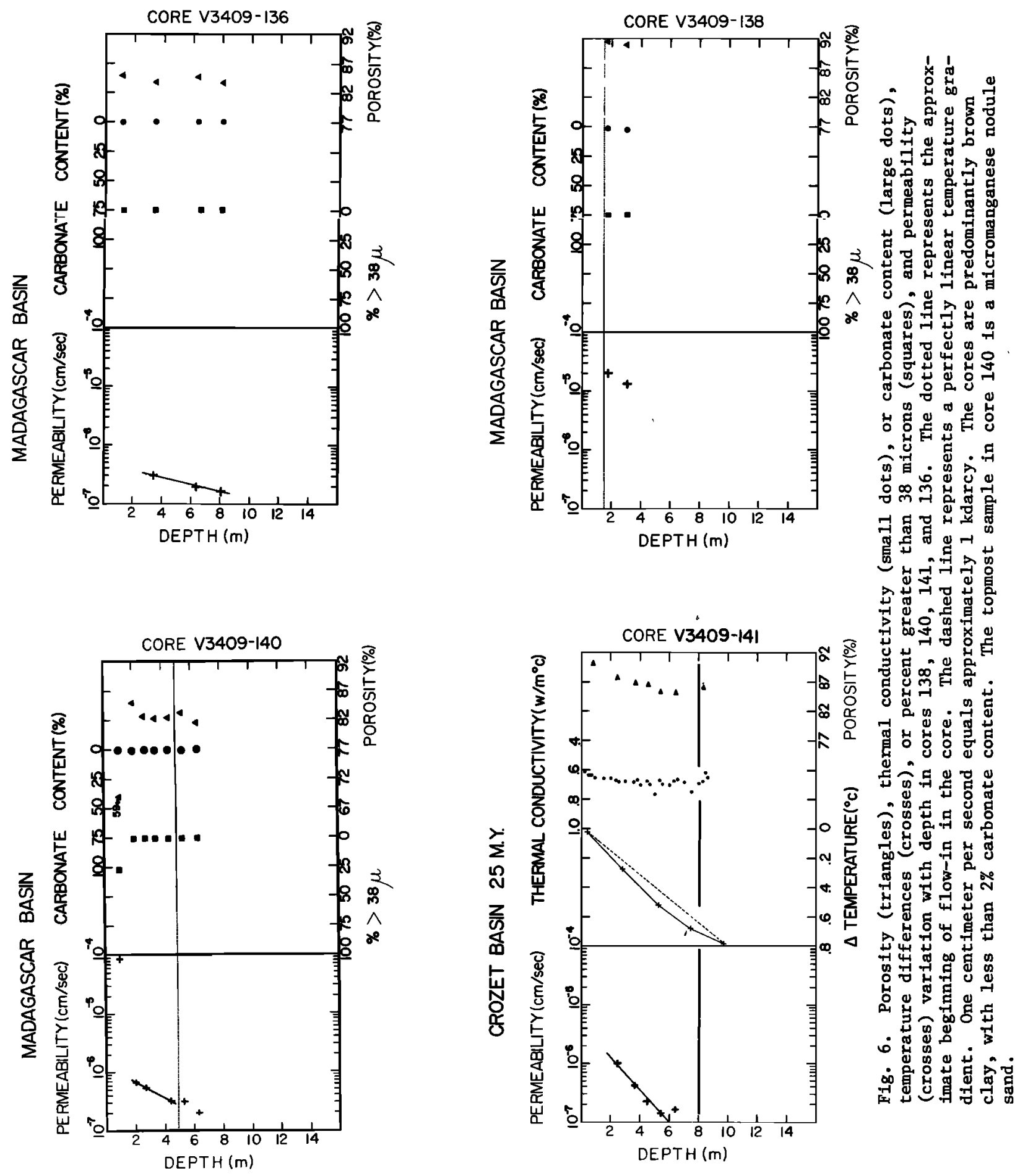
oratory experiments and so can support substantial excess pore pressures for some period of time, (2) the water movements causing the nonlinear temperature gradients are predominantly horizontal rather than vertical, and (3) the laboratory measurements of permeability are lower than the in situ values.

The cohesion intercept ( $\bar{c}$ ) for clay-rich terrestrial soils varies from $4.8-24 \mathrm{kN} / \mathrm{m}^{2}(4.8-$ $2.4 \times 10^{5}$ dynes $/ \mathrm{cm}^{2}$ ) [Lambe and Whitman, 1979, p. 316]. The greatest difference between the calculated overburden pressure and the excess pore pressure (gradient of 10 in core 141) is $1.2 \times 10^{6}$ dynes $/ \mathrm{cm}^{2}$, much higher than the maximum measured values of the cohesion intercept in terrestrial clays. If we assume that the clay in core 141 has the maximum cohesion intercept, then the ratio of the excess pore pressure to overburden pressure plus cohesion intercept is still a factor of 3 . The cohesion intercept of in situ marine clays would have to be 3 times higher than laboratory values to explain this inconsistency. This is unlikely to be a viable alternative because water content and cohesion intercept are inversely related. The water contents of the terrestrlal clays with the highest cohesion intercept are less than $25 \%$. In contrast, the marine clays in the southwest Indian Ocean have water contents from 80 to $91 \%$. It thus appears likely that the cohesion intercept of the clays in the survey areas is much less than the maximum values obtained in laboratory experiments upon terrestrial samples.

Horizontal water movement along the sedimentary layers can generate nonlinear temperature profiles, provided that a source of anomalously hot or cold water is nearby. A vertical crack in the sediment or a steep abyssal hill can act as a source for this water. Both cores V31-141 and v34-177 are located in regions of rough topography which are possible locations of sources of this kind. Horizontal water movement can dominate vertical water movement because a horizontally layered material has a vertical permeability controlled by the most impermeable layer but a horfzontal permeability determined by the most permeable layer [Lambe and Whitman, 1979, p. 275].

Additionally, the presence of small fluctuations of porosity about the normal increase with depth can cause large differences in the permeabilities of nearby layers. This is because a change in porosity of a few percent can cause an order of magnitude change in the permeability (F1gure 6). Cores 136,138,141, and 140 are the best examples of this because they lack carbonatecontaining surface layers. The $1-2 \%$ fluctuations In porosity will not substantially affect the vertical permeability but may cause the average horizontal permeablitty to be much higher than the vertical permeability. The platelike shape of the clay mineral particles, which tend to align themselves with their long axis horlzontally as compaction proceeds, would further increase the difference between the average horizontal and vertical permeabilities. A ratio of horizontal to vertical permeability of 2 to 10 times is common in normally consolidated terrestrial clay [Lambe and Whitman, 1979, p. 275].

We have developed a simple model of horizontal water movement with which we can study the shape of the temperature profile and the rate at which nonlinearities in the temperature profile decay as the distance from the anomalous water source increases (Appendix A). In our model, water enters the sediment from a vertical surface at a constant temperature and then flows horizontally (Figure 9). The water velocity is controlled by the permeability of the sediment, which may be constant or decrease with depth. When the sediment has a constant permeability, the temperature profiles are bow shaped. The bow is concave upward when the temperature of the anomalous water at its source is near the bottom water temperature. The bow is concave downward when the temperature of the source water is relatively warm. Horizontally moving cold water produces a temperature profile similar in shape to one caused by downward vertical flow, while horizontally moving water produces a profile similar to that caused by upward vertical flow. When sediment permeability decreases with depth, the shape of the temperature - profile becomes increasingly distorted (Figure 10).

The degree of nonlinearity depends upon the velocity of the horizontally moving water, the size of the source, and the distance from it. For an average horizontal permeability of $5 \mathrm{x}$ $10^{-6} \mathrm{~cm} / \mathrm{s}$ and a $10-\mathrm{m}-10 \mathrm{ng}$ source some nonlinearity should be visible up to about $6 \mathrm{~m}$ away from the source.

The vertical permeability of core V34-144 is nearly constant with depth and has a value of $5 \times 10^{-7} \mathrm{~cm} / \mathrm{s}$. Even if we assume the horizontal permeability is 10 times larger than this value, sources that affect the temperature profile must be within $6 \mathrm{~m}$ of the core. The nearest outcrop to this core $1 \mathrm{~s} 80 \mathrm{~m}$ distant, but the presence or absence of cracks was not determined. Core v34-141 has a surface vertical permeability which rapldly decreases with depth. Anomalous water sources that affect this core must be no more than about $16 \mathrm{~m}$ distant, while no outcrops are observed within 200 m of the core. Therefore we can discount basement outcrops as sources for nonlinear temperature profiles for both of these cores. Cracks in the sediment are unlikely sources for the nonlinear temperature profiles in cores 141, 142, and 144. All of these cores have convex upward temperature profiles which would require horizontal movement of warm water emitted from a crack. The lower part of the crack would need to be kept open by the water flow, yet the crack could not extend to the surface or horizontal flow would not occur. The cracks would need to stop within centimeters of the surface to produce the temperature profiles that we observe. This seems unnecessarily fortuitous. Additional$1 y$, worm burrows are often preserved at several meters depth within cores, so that fractures if they exist should have been observed. We did not observe cracks in the Indlan Ocean cores nor do we know of any fractures at depth in other deep sea cores. We thus feel that warm water cracks are unlikely sources of the nonlinear temperature gradients we observed. Thus, although we cannot rule out horizontal water movement in every case, it is not the cause of the nonlinear gradients in cores 144 and 141.

Another possibility is that the permeabilities we measured in the $1 \mathrm{ab}$ are actually lower than the in situ values of the permeability. Our device measured the saturated sample at about 1 bar, but the in situ pressure is about 500 bars. Although our measurements as a group agree with those of 
TABLE 1. Summary of Core Data

\begin{tabular}{|c|c|c|c|c|c|c|c|c|}
\hline \multirow{2}{*}{$\begin{array}{c}\text { Age of } \\
\text { Oceanic } \\
\text { Crust (my) }\end{array}$} & \multirow{2}{*}{$\begin{array}{c}\text { Core } \\
\text { Number }\end{array}$} & \multirow{2}{*}{$\begin{array}{l}\text { Slope of } \\
\text { Permeabi- } \\
\text { lity - } \\
\text { Depth } \\
\text { Profile } \\
\text { (Decades/m) }\end{array}$} & \multirow{2}{*}{$\begin{array}{l}\text { Depth of } \\
\text { Core Bar- } \\
\text { rel Pene- } \\
\text { tration / } \\
\text { Good Core } \\
\quad(\mathrm{cm})\end{array}$} & \multirow{2}{*}{$\begin{array}{l}\text { Amount of } \\
\text { Flow-in in } \\
\text { Core } \\
(\%)\end{array}$} & \multicolumn{2}{|c|}{$\begin{array}{c}\text { Grain Size Distri- } \\
\text { bution }\end{array}$} & \multirow{2}{*}{$\begin{array}{l}\text { Proportion } \\
\text { of Non- } \\
\text { linear } \\
\text { Temperature } \\
\text { Profiles in } \\
\text { Area ( } \%)\end{array}$} & \multirow{2}{*}{$\begin{array}{l}\text { Approx- } \\
\text { Imate Sur- } \\
\text { face Sedi- } \\
\text { mentation } \\
\text { Rate (m/my) }\end{array}$} \\
\hline & & & & & $\begin{array}{l}\%>38 \mu \\
\pm 0.1 \%\end{array}$ & $\begin{array}{l}\%>4 \mu \\
\pm 10 \%\end{array}$ & & \\
\hline 55 & 136 & 0.05 & $1210 / 1006$ & 0 & 0.18 & 75 & 46 & 4 \\
\hline 55 & 138 & - & $235 / 158$ & 59 & - & - & 46 & 4 \\
\hline 55 & 140 & 0.13 & $725 / 563$ & 14 & 1.02 & 62 & 46 & 4 \\
\hline 25 & 141 & 0.28 & $1020 / 800$ & 23 & 0.39 & 68 & 59 & 2 \\
\hline 45 & 142 & - & $1615 / 1016$ & 42 & 0.77 & 33 & 33 & 3 \\
\hline 18 & 143 & -- & $106 / 106$ & 0 & 35.00 & 45 & 65 & 1 \\
\hline 18 & 144 & 0.04 & $\begin{array}{r}1110 / 660 \rightarrow \\
895 ?\end{array}$ & $0 ?<27$ & 0.30 & 65 & 65 & 1 \\
\hline$>55$ & 145 & -- & $? / 514$ & 0 & $49 / 26 / 1$ & 89 & $-\infty$ & $>1.5 *$ \\
\hline$>55$ & 148 & 0.10 & $1180 / 1006$ & 5.2 & 6.00 & 77 & -- & $>6.6 *$ \\
\hline$>80$ & 151 & 0.33 & $450 / 370$ & 0 & 20.00 & 55 & -- & $>2.0 *$ \\
\hline$>80$ & 155 & 0.48 & $? / 230$ & 0 & 37.00 & 41 & -- & $>2.9 *$ \\
\hline$>80$ & 156 & 0.13 & $605 / 516$ & 0 & 21.00 & 53 & - & $>1.3 *$ \\
\hline
\end{tabular}

* Determined from dating of the base of fossiliferous plateau and ridge cores.

Bryant et al. [1970] for clays, none of the existing measurements have been done at pressures higher than about 20 bars. Measurements do exist for the electrical resistivity of montmorillonitic clay-water solutions for pressures between zero and 2500 bars [Lang, 1967]. The resistivity of the montmorillonite-water solution increases irregularly for pressures between zero and 500 bars, while above 500 bars the resistivity changes smoothly with pressure. Lang [1967] attributes this behavior to the loss of adsorbed water on the clay mineral surfaces, which becomes complete at 500 bars. Adsorbed water on clay mineral surfaces would cause measurements at low pressures to underestimate the in situ permeability. Since the clay fraction of sediments from the southwest Indian Ocean tends to have a high montmorillonite content (50-70\%) [Kolla, 1976], such a mechanism could be important in determining the in situ permeability of the sediments. There is thus a great need for the development of in situ permeability measurement capabilities.

Aside from the problem of duplicating in situ conditions, there is also the problem of sediment disturbance. As cited previously, remolding of sediments can lower the permeability by a factor of 3 to 60 [Lambe and Whitman, 1979, p. 291]. Even a small amount of disturbance could lower the permeability sufficiently to cause a discrepancy between the measured permeabilities and the calculated water velocities. In addition to this, the higher the excess pore pressures, the lower the strength of the sediment will be. This is because the strength of a sediment is proportional to the effective stress (the overburden pressure minus the pore pressure) rather than the total stress (the overburden pressure) [Lambe and Whitman, 1979, p. 241]. The sediments with the highest excess pore pressures will thus be the most likely to be remolded, with consequent lowering of the measured permeability.

What evidence exists for sediment remolding during coring? Remolding caused by high excess pore pressures may result in the presence of large amounts of material classifled as flow-in. Both cores 141 and 142 have large amounts of flow-in and nonlinear temperature gradients. The depths of penetration in both cores are constrained to within $10 \mathrm{~cm}$ by the heat flow. Flow-in is core material that looks disturbed and appears turbulently mixed with most layering vertical rather than horizontal. The traditional view of flow-in is that it is material sucked in by the core pipe as the pipe is removed from the bottom. In such a case the core should be longer than the total depth of penetration. In the case of core 142 the core is $1700 \mathrm{~cm}$ long with $1615 \mathrm{~cm}$ of penetration. Of the $1700 \mathrm{~cm}$ of core, $700 \mathrm{~cm}$ are classed as flow-in. In order for all of this material to be the result of the pullout the core would need to have triggered $6 \mathrm{~m}$ too late and then to have drawn in $7 \mathrm{~m}$ of material on the pullout. Core 141 has $1021 \mathrm{~cm}$ of penetration and is $1078 \mathrm{~cm}$ long; $278 \mathrm{~cm}$ of this core are classifled as flowin. In order for all the material in the pipe classed as flow-in to be displaced material, a $220-\mathrm{cm}$ late trigger and $278 \mathrm{~cm}$ of material pulled in upon with withdrawal of the core are reeded.

An alternative interpretation is that most of the material classified as flow-in is actually drawn in during the penetration of the core pipe. If water velocities indicated by the heat flow measurements are correct, excess pore pressures which approach the overburden pressure are predicted at shallow depths in the sediment. Such a highly overpressured zone could easily be fluidized by the impact of coring. This liquified material could then be turbulently sucked into the core pipe during penetration. Material from such an overpressured zone would show a virtually constant permeability with increasing depth, precise1y what we see in material classified as flow-in in cores 141 and 142 .

Flow-in is quite common in the cores from areas 

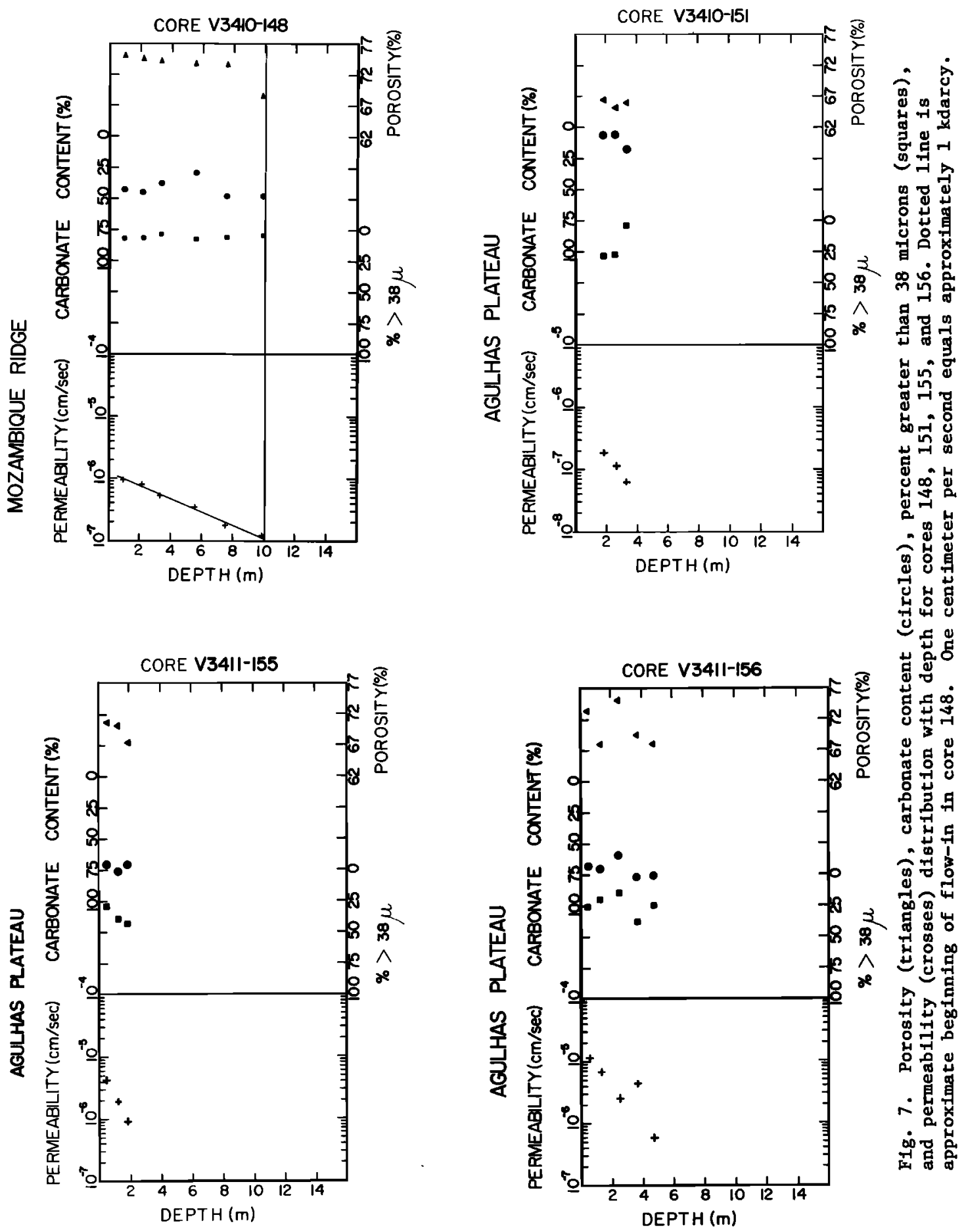
wth nonlinear gradients, while only one of the calcareous cores has flow-in (see Table 1). Although flow-in could be partially related to a high clay content, the calcareous cores discussed below have analogous clay percentages, so that the difference in amount of flow-in is indeed significant. Among the red clay cores where flow-in is absent, core 136 is from the deepest and oldest seafloor (Figure 5), while core 143 has high permeability and rock fragments at its base. We are ignorant of flow-In in core 144 because the last pipe was lost in transit, but it is definitely less than $27 \%$ of the core.

The evidence from flow-in thus appears to support the idea that excess pore pressures do indeed exist in the core locations where nonlinear temperature gradients were measured. This would tend to support the Idea that water is moving through the sediment, as the heat flow measurements suggest. The laboratory measurements of permeabllity would have to be low by only an order of magnitude in order to resolve the discrepancy between velocities calculated from heat flow versus permeability, assuming that significant excess pore pressures exist. Such a variation in permeability from in situ to laboratory conditions is well within the range of changes caused by remolding.

What other evidence exists for high excess pore pressures in the sediment of the Madagascar and Crozet basins? Abyssal hills and hillsides which are virtually bare of sediment are visible in the areas of nonlinear gradients, particularly in the 18 and $25 \mathrm{~m} . \mathrm{y}$. old survey areas (Figures 5 and 2). The amount of sediment cover seems partially but not totally related to the steepness of the topography. Although current activity could be the cause of the uneven sediment cover, another possibility is that areas of upwelling water cause perlodic sediment slides or slumps on topographic highs. Because the compaction of sediment under its own weight produces a decrease in permeability with depth, a constant flux of water through the sediment will produce an increase in excess pore pressure with depth (APpendix B). Thus when the excess pore pressure in the sediment exceeds the combined force of the overburden pressure and the cohesive strength of the sediment, the cover becomes unstable and slides or slumps. The critical thickness would depend upon the permeability and the rate of water movement through the sediment. Such slumps or slides might produce graded bedding but not of the classic form, since brown clays are all fine grained. Instead of graded bedding discernable to the naked eye the grading of the beds would only appear as the result of careful grain size work. Such grading could produce local variations in porosity, permeability, and thermal conductivity. We found probable slump masses on the $3.5 \mathrm{kHz}$ records for cores $\mathrm{v} 34-143$ and v34144 (Figure 3). We were unable to use fossils in this area to detect slumping because the cores have no fossils or a few severely dissolved fossils.

The average apparent sedimentation rate of the survey areas increases with age (Table 1), an observation possibly attributable to overpressures. The major sources of sediment in the three younger survey areas are predominantly pelagic and weathered basement material. All cores are from below the Carbonate Condensation Depth (CCD). In this case, one would expect the youngest areas to have the highest rather than the lowest average apparent sedimentation rate. Compaction effects and Increased seismic velocity would tend to accentuate the expected higher sedimentation rate in younger areas. The effects of water movement provide a mechanism for lowering the sedimentation rate in the youngest areas, since sediment slides or slumps of fine-grained material would facilitate resuspension and removal by currents. In areas of rapid water movement the fluxes we calculate are high enough to prevent Stokes law settling of very fine material (less than $1 / 2 \mathrm{mi}-$ cron).

\section{Calcareous Sands and Muds}

The cores containing calcareous sands and muds have no heat flow data, but large amounts of water movement are considered unlikely due to the locations of the cores (Figure 1) [Anderson et al., 1977]. The hills and ridges in these areas are continuously draped with sediment, even upon fairly steep slopes (Figures 2 and 3 ).

The $3.5-\mathrm{kHz}$ record for core 145 shows a layered sediment with no probable slump masses, even on the steep slope at the far right (Figure 3 ).

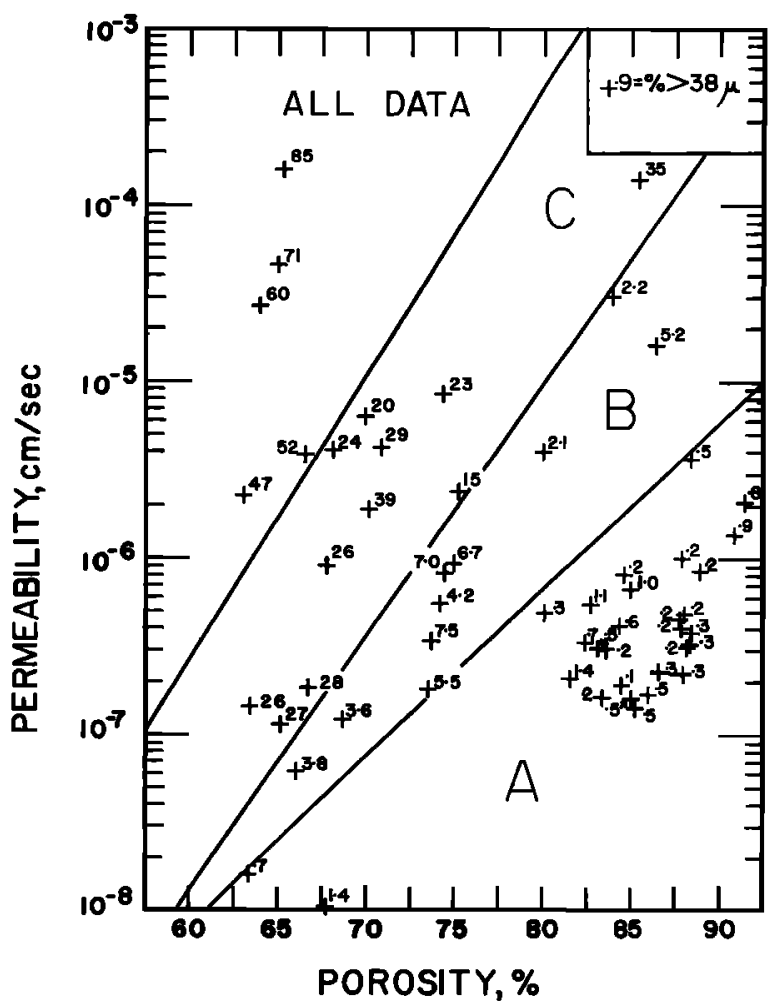

Fig. 8. Permeability plotted versus porosity for all samples. The numbers next to the sample data points (crosses) represent the percent of the sample larger than 38 microns. The three groupings ( $A, B$, and $C$ ) represent samples with the following range of percent coarse fraction: $A$, less than $1.5 ; \mathrm{B}, 1.5 \rightarrow 15 ; \mathrm{C}, 15+50$. Notice that the rate of change of permeability for the same change in porosity is higher in groups $B$ and $C$ than it is in group A. One centimeter per second equals approximately 1 kdarcy. 
TABLE 2. The Constants $A_{i}, B_{i}, C_{i}$ (the Top, Middle and Bottom Number of Each Group) for several values of $i$ and $p$

\begin{tabular}{rrrrr}
\hline $\mathrm{p}=0$ & $\mathrm{p}=1$ & & $\mathrm{p}=2$ & $\mathrm{p}=3$ \\
\hline-1.414 & -0.908 & $\underline{\mathrm{n}=1}$ & -0.670 & -0.531 \\
+2.828 & +2.374 & & +2.165 & +2.044 \\
+3.141 & +2.903 & & +2.781 & +2.707 \\
-1.000 & -0.561 & $\underline{\mathrm{n}=2}$ & -0.384 & -0.289 \\
0.000 & -0.458 & & -0.645 & -0.744 \\
+6.283 & +6.033 & & +5.906 & +5.830 \\
-0.816 & -0.425 & & -0.279 & -0.206 \\
+1.632 & +1.251 & & +1.112 & +1.042 \\
+9.425 & +9.170 & & +9.042 & +8.965 \\
-0.707 & -0.349 & $\underline{n}=4$ & -0.224 & -0.162 \\
0.000 & -0.363 & & -0.490 & +0.552 \\
+12.566 & +12.305 & & +12.174 & +12.095 \\
\hline & & & & \\
\hline
\end{tabular}

Erosion effects are definitely present, but there is no evidence of the acoustically vague, unlayered sediment which occurs near cores v34-143 and 144. However, an extrapolation of the surface trends would produce quite low permeability at depths of several tens of meters. These permeabilities are low enough so that excess pore pressures could develop in the presence of high water fluxes. Thus the absence of bare slopes of basement rock might be evidence against high excess pore pressures and water fluxes in this region.

With the exception of core 145, all of the calcareous sands and muds have a relatively sma11 range of grain sizes. Cores 148, 151, 155, and 156 all show a semilog rate of decrease of permeab1lity with depth. This is probably again attributable to a linear fall off of the average porosity with depth (see Figure 7). Because of larger local deviations in the porosity this effect is not as obvious, but it is present. The importance of this semilog fall-off of the permeab1lity with depth is that it predicts quite low permeability at shallow depths in the sediment, provided that compaction is not affected by excess pore pressures. Although the compaction at the surface is no doubt more rapid than that which occurs at depth, very low permeabilities are still likely at shallow depths.

The other importance of the semilog pattern is that the slope of the permeability-depth profile is correlatable with the average percent coarse fraction (Table 1). This is not too surprising, since the higher percent coarse fraction material has a greater average permeability (see Figure 8 ). Thus percent coarse fraction, porosity, and permeabllity are all intimately related. A marine materlal with a higher percent coarse fraction will compact more quickly for three reasons, (1) it has a higher permeability, (2) the fossils which are in the coarse fraction crush easily, and (3) fossils, heavy minerals, and rock fragments do not have adsorbed water on their surfaces, as clay minerals do.

The contrast between the calcareous material and the brown clays points out the importance of grain size distribution in determining the slope of permeability-depth profiles. These profiles have the potential to be used as indicators of the effects of excess pore pressure and water movement upon the compaction of the sediment, but the effect of grain size distribution must first be removed.

\section{Summary}

We have presented a number of lines of evidence that excess pore pressures do exist in the areas of red clay sediment in the southwest Indian Ocean: (1) the presence of turbulently mixed material at the bases of cores with nonlinear temperature gradients and low permeability, (2) the lack of sediment cover on hillsides and hilltops in the red clay areas, whereas similar features which are present on the aseismic ridges and plateaus are thickly sedimented, (3) the increasing average apparent sedimentation rate with age in the Crozet and Madagascar basins, and (4) the presence of nonlinear temperature gradients and sediments of low permeability in the Madagascar and Crozet basins.

There are still a number of contradictions; the most important of which is that the laboratory measurements of permeability appear to be too low to allow water movement. Because the major disturbing effects of coring would all act to cause the laboratory measurements of permeability to be lower than their in situ values, we belleve that an in situ measurement program of permeability and excess pore pressure is necessary. Measurements of these two variables would show definitively the presence or absence of the water fluxes indicated by the heat flow and other data.

We are presently attempting to measure both in situ excess pore pressures and permeability in locations which are known to have nonlinear temperature gradients. We are also working with geochemists to do pore water studies on cores with heat flow and excess pore pressure measurements. These measurements, which are all independent, should help us to resolve our present problems. 
Appendix A: Horizontal Water Movement and Temperature Profiles

The Model. We will consider a sediment of uniform therma1 properties that in the absence of horizontal water movement has a linear temperature profile. At a reference depth $z=0$ in the sediment the temperature is $T_{B^{*}}$ At the top of the sediment, $z=\mathrm{L}$, the temperature is zero. We will calculate the effect of water which enters a vertical crack at temperature $\mathrm{T}_{c}$ located at a horizontal range $x=0$. The crack extends vertically from $z=0$ to $z=L$. The water velocity varies with depth, since it is proportional to the sediment's permeability. We will assume that the variation can be adequately represented by a known function of depth $V_{H}(z)=$ $V(z / L)^{P}$, where $V$ is the horizontal pore-fluid velocity at the top of the sediment and $p$ is an integer describing how fast the velocity decreases with depth (that is, increases with $z$ ). This geometry is shown in Figure 9.

We w111 also assume that the temperature distribution does not vary with time and that heat is transferred vertically only by conduction and horlzontally only by water movement. Under these circumstances the equation of heat flow is:

$$
\text { ap c } V_{H}(z) \frac{\partial T}{\partial x}=k \frac{\partial^{2} T}{\partial x^{2}}
$$

where $\rho$ and $c$ are the density and heat capacity of sea water, respectively, and $n$ and $k$ are the porosity and thermal conductivity of wet sediment, respectively.

The Solution. The temperature distribution is then given by [see Hildebrand, 1962, p. 158] :

$$
\begin{gathered}
T(x, z)=T_{B} \times(1-z / L)+ \\
\sum_{i=1}^{\infty}\left[A_{1} T_{B}+B_{1} T_{c}\right](z / L) \frac{1}{2} \frac{J_{1}}{p+2}\left[C_{i}(z / L) \frac{p+2}{2}\right] \exp \\
\text { where } D=-\frac{1}{4} \quad C_{1} 2(p+2) \frac{k}{n \rho_{c V}} \frac{x}{L^{2}}
\end{gathered}
$$

Here $J$ is the fractional order Bessel function of the first kind, and $A_{1}, B_{1}$, and $C_{1}$ are constants (see Table 2).

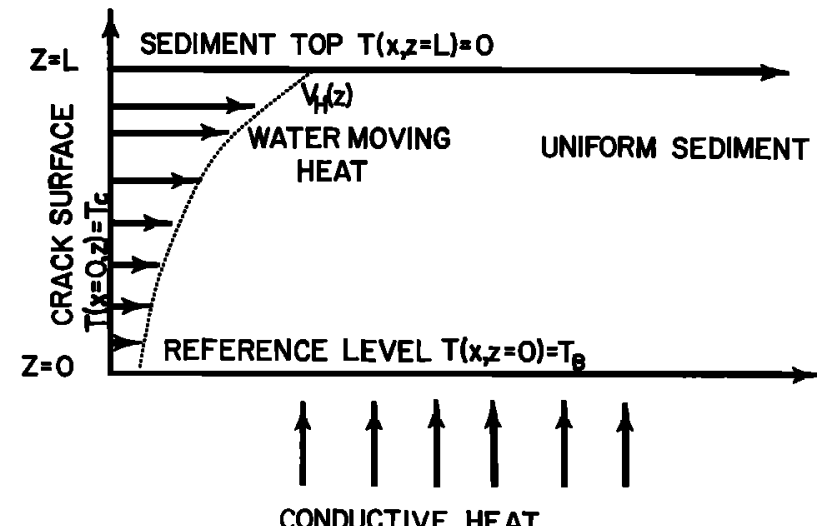

F ig. 9. Schematic of problem showing geometry and boundary conditions.
TABLE 3. The Critical Crack Temperature

\begin{tabular}{|c|c|c|c|c|}
\hline & $\mathrm{p}=0$ & $\mathrm{p}=1$ & $\mathrm{p}=2$ & $\mathrm{p}=3$ \\
\hline $\begin{array}{l}\mathrm{T}_{\mathrm{c}} \text { (critical, } \\
\% \text { of } \mathrm{T}_{\mathrm{b}}\end{array}$ & 0.500 & 0.382 & 0.309 & 0.260 \\
\hline$\left.X_{c},{ }^{m}=5 \times 10^{-6} \mathrm{~cm} / \mathrm{s}\right)$ & 2.66 & 1.39 & 0.84 & 0.57 \\
\hline$\left.x_{c},{ }_{(v}^{m}=5 \times 10^{-5} \mathrm{~cm} / \mathrm{s}\right)$ & 26.0 & 13.9 & 8.4 & 5.7 \\
\hline
\end{tabular}
$\mathrm{T}_{\mathrm{c}}$ (critical) and the characteristic distance $x_{c}$ as a function of $p$ (1.e. the velocity depth profile)

Calculations are for the data given in Figure 10 and two different water velocities.

The first term in the solution contains the linear gradient. At very large ranges, corresponding to distances far from the crack where the water temperature has completely equilibrated, the exponentials cause the terms in the summation to be nearly zero. At these large ranges the temperature profile is nearly linear. Since the constants $C_{1}$ rapidly increase with 1 , only the first term of the summation is important at intermediate ranges. Then the temperature profile consists of a linear gradient modified by a bow shaped Bessel function. The size of the bow depends upon the size of the exponential. The characterlstic decay distance (see Table 3 ) is given by:

$$
x_{c}=-\frac{4}{c_{1}^{2}(p+2)^{2}} \frac{n p c V}{k} L^{2}
$$

For reasonable choices of the constants the characteristic distance 1 s between $I$ and $20 \mathrm{~m}$. Depending upon the crack temperature, the bow shaped Bessel function is either added to or subtracted from the linear gradient. For crack temperatures near zero (the bottom water temperature) the temperature is less than that of a linear gradient

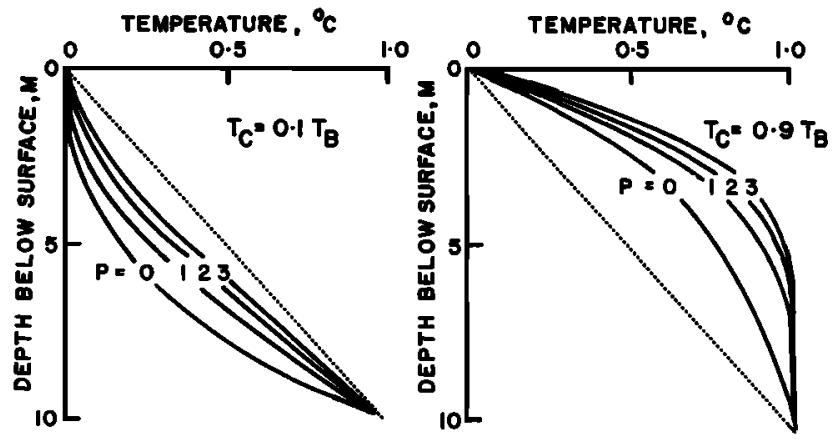

Fig. 10. Plot of temperature-depth profile for two different cholces of $T_{c}$ and for several different velocity-depth functions $(p=0,1,2,3)$. The average velocity in the interval from 0 to $L$ is the same in all cases; $V_{H}=5 \times 10^{-5} \mathrm{~cm} / \mathrm{s}$. The dotted line is the linear gradient. Constants used (oceanic sediment): $=1.04 \mathrm{~g} / \mathrm{cm}^{3} ; \mathrm{k}=1.6 \mathrm{x}$ $10^{-3} \mathrm{cal} / \mathrm{s} \mathrm{cm}{ }^{\circ} \mathrm{K} ; \mathrm{c}=0.9 \mathrm{cal} / \mathrm{g}{ }^{\circ} \mathrm{K} ; \mathrm{n}=0.9 ; \mathrm{L}=$ $10 \mathrm{~m} ; \mathrm{x}=10 \mathrm{~m} ; \mathrm{T}_{\mathrm{B}}=1.0^{\circ} \mathrm{C}$. 
TABLE 4. Overburden Pressure and Excess Pore Pressure Calculated for Core V34-141

\begin{tabular}{ccc}
\hline Depth, m & $\mathrm{P}_{0}$, dynes $/ \mathrm{cm}^{2}$ & $\mathrm{P}_{\mathrm{e}}$, dynes $/ \mathrm{cm}^{2}$ \\
\hline 1 & $1.5 \times 10^{4}$ & $3.9 \times 10^{3}$ \\
2 & $3.3 \times 10^{4}$ & $3.3 \times 10^{4}$ \\
3 & $5.3 \times 10^{4}$ & $1.3 \times 10^{5}$ \\
4 & $7.5 \times 10^{4}$ & $3.4 \times 10^{5}$ \\
5 & $9.8 \times 10^{4}$ & $7.1 \times 10^{5}$ \\
6 & $1.2 \times 10^{5}$ & $1.3 \times 10^{6}$ \\
\hline
\end{tabular}

(bow subtracted). For crack temperatures near $T_{B}$ it is greater (bow added). The temperature at which the bow neither adds or subtracts, the critical temperature $T_{c}$ (critical) is (see Table 3 and Figure 10):

$$
T_{c}(\text { critical })=-A_{1} T_{B} / B_{1}
$$

In the case of a constant horizontal water velocity $(P=0)$, the critical crack temperature equals (as expected) the average of the temperature at the top and bottom of the sediment.

Append1x B: Overburden Pressure and Excess Pore Pressure Calculated for Core 141

Core 141 had the highest upward water flux of those cores observed to have nonlinear temperature gradients. The following relations [from Lambe and Whitman 1979] were used to calculate the excess pore pressure, $\mathrm{P}_{\mathrm{e}}$ and the overburden pressure $\mathrm{P}_{\mathrm{O}}$ :

$$
\begin{gathered}
P(z)=\int_{0}^{z} \frac{\rho_{w} g v(z) n(z)}{k(z)} d z \\
P(z)=\int_{0}^{z}\left(\rho_{5} \rho_{w}\right) g[1-n(z)] d z
\end{gathered}
$$

Here $\rho_{W}$ and $\rho_{s}$ are the densities of water and sediment particles, $g$ is the gravitational acceleration, $v(z)$ is the water velocity in the sediment, and $n(z)$ is the porosity as a function of depth. The product $n(z) v(z)$ is a constant, here $1 \times 10^{-6} \mathrm{~cm} / \mathrm{s}$.

Calculations based on these relations, shown in Table 4, predict that the excess pore pressure exceeds the overburden pressure at only $2 \mathrm{~m}$ depth. If this were so, the permeability would cease to decrease or decrease very slowly below $2 \mathrm{~m}$. In actuality, the permeability continues to decrease rapidly until $6 \mathrm{~m}$ depth, where it attains a value (measured $1 \mathrm{n} \mathrm{cm} / \mathrm{s}$ ) which is less than $1 / 10$ the predicted water velocity. All samples below this depth are classed as flow in.

As discussed earlier, we believe that this flow-in is largely material which had an initial in situ excess pore pressure. The 1mpact of coring caused fluidization of this zone, which then flowed in during penetration of the core pipe.
The amount of excess pore pressure generated by the coring process itself would determine the in situ excess pore pressure necessary for fluidization.

Acknowledgments. We thank Christopher Scholz and Robert Stohl for their review of the original manuscript and for the improvements they suggested. We also thank Peter Thompson for his help in determining sedimentation rates. Ron Hadley, Glenn Jones, and John Crowe provided suggestions and advice, and the officers and crew of the $R / V$ VEMA assisted in gathering the data. Hester Haring Cason patiently typed the manuscript. This research was supported by the National Science Foundation under grant OCE 78-20445 and the Office of Naval Research under grant T0210-SCOPE T. One of the authors (W.M.) was supported by National Science Foundation graduate fellowship and the senior author was supported by the Boris Bakhmeteff fellowship in fluid mechanics of Columbia University. Lamont-Doherty Geological Observatory contribution 3069.

\section{REFERENCES}

Anderson, R. N., M. G. Langseth, and J. G. Sclater, The mechanisms of heat transfer through the floor of the Indian Ocean, J. Geophys. Res., 82, 3391-3409, 1977.

Bredehoeft, J. D., and I. S. Papadopulos, Rates of vertical groundwater movement estimated from the earth's thermal profile, Water Res., 1 , 325-328, 1965.

Bryant, W. R., W. Hottman, and P. T. Trabant, Permeability of unconsolidated and consolidated marine sediments, Gulf of Mexico, Mar. Geotech., $1,1-13,1970$.

Embley, R. W., and R. D. Jacobi, Distribution and morphology of large submarine sediment slides and slumps on Atlantic continental margins, Mar. Geotech. 2, 205-227, 1977.

Hildebrand, F.B., Advanced Calculus for Applications, Prentice-Ha11; Englewood Cliffs, N. J., 1962.

Keller, G. H., and R. H. Bennett, Sediment mass physical properties-Panama Basin and northeastern equatorial Pacific, Initial Rep. Deep Sea Drill. Prof., 16, 499-512, 1973.

Kolla, V., L. Henderson, and P. Biscay, Clay mineralogy and sedimentation in the western Indian Ocean, Deep Sea Res., 23, 949-961, 1976.

Lambe, W. T., and R. V. Whitman, Soll Mechanics, John Wiley, New York, 1979.

Lang, W. J., The influence of pressure on the electrical resistivity of clay-water systems, Conf. Clays Clay Minerals, 15th, 455-468, 1967.

Parsons, B., and J. G. Sclater, An analysis of variation of ocean floor heat flow and bathy-

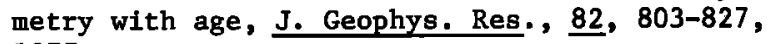
1977.

Saito, T., L. H. Burckle, and J. D. Hays, Impl1cations of some pre-Quaternary sediment cores and dredging studies in paleooceanography, S.E.P.M. Short Course, 20, 6-36, 1974.

Schlich, R., Structure et age de I'Océan Indien Occidental, Mem. Soc. Geo1. Fr., 6, 1975.

Simpson, E. S. W., et al., Leg 25 DSDP western Indian Ocean, Geotimes, 21-24, 1972.

Trabant, P. K., Synthesis of physical properties 
data from DSDP leg 41, Initial Rep. Deep Sea Dril1. Proj. , 41, 1199-1213, 1977 .

Trabant, P. K., W. R. Bryant, and A. H. Bouma, Consolidation characteristics of sediments from leg 31 of the Deep Sea Drilling Project, Initlal Rep.Deep Sea Drill. Proj. , 31, 425-432, 1975. Tucholke, B. E., and G. B. Carpenter, Sediment distribution and Cenozoic sedimentation patterns on the Agulhas Plateau, Geol. Soc. Am. Bull., 88, 1337-1346, 1977.

(Received April 7, 1980;

revised August 1, 1980;

accepted August 20,1980.) 